\title{
Sizing Optimization of Hybrid Stand Alone Photovoltaic System
}

\author{
Zulkifli Othman", Shahril Irwan Sulaiman", \\ Ismail Musirin", Ahmad Maliki Omar", Sulaiman Shaari", Muhammad Zakyizzuddin Rosselan ${ }^{\#}$ \\ \#Faculty of Electrical Engineering, Universiti Teknologi Mara (UiTM) Selangor, Malaysia \\ E-mail: zulkifli_1980@yahoo.co.uk, shahril_irwan2004@yahoo.com,ismailbm@salam.uitm.edu.my,ambomaliki@gmail.com, \\ zaky_rosselan@yahoo.com.my
}

*Faculty of Applied Sciences, Universiti Teknologi Mara (UiTM) Selangor, Malaysia

E-mail: solarman1001@ gmail.com

\begin{abstract}
This paper presents a sizing optimization technique for Hybrid Stand-Alone Photovoltaic (HSAPV). In this study, two optimization techniques based on the mechanics of Evolutionary Programming (EP) have been developed, namely Fast Evolutionary Programming (FEP) and Classical Evolutionary Programming (CEP). These techniques have been integrated into the sizing process to maximize the technical performance of the HSAPV system. It is used to determine the optimum PV modules, charge controllers, inverters, battery and diesel generator. These variables are used as the control parameters to maximize the expected performance ratio (PR) of the HSAPV system. Comparative studies with respect to a benchmarking technique namely the Iterative Sizing Algorithm (ISA) were conducted in order to reveal their merit in terms of achieving maxima PR value and minimal computation time. Results obtained from the study exhibited that FEP outperformed CEP. The developed FEP and CEP also demonstrated comparatively fast with respect to ISA as the benchmark technique.
\end{abstract}

Keywords — evolutionary programming (EP); fast evolutionary programming (FEP); classical evolutionary programming (CEP)

\section{INTRODUCTION}

Nowadays, fossil fuel sources around the world have attracted the world community to find a solution, in respect of energy security in the future. Apart from fuel, renewable energy has been known as an alternative which has been widely used to reduce dependency on electricity produced by the fuel. Among renewable energy, PV energy is widely used than others [1]. Although there are various types of renewable energy technologies, solar photovoltaic (PV) has become one of the promising renewable energy technologies, especially in rural areas that are usually deprived of the electric grid. The photovoltaic system is the most promising ways to produce electricity directly convert sunlight into electricity easily [2]. Example of solar PV system used for rural electrification is Hybrid Stand-Alone Photovoltaic system (HSAPV).

HSAPV system usually consists of PV modules, such as power conditioning unit charge controller and inverter, a battery bank for storage charges and diesel generator (DG). The diesel generator of HSAPV system equally charges the battery bank when it runs at full power (cycle charging control strategy). Therefore, in such situation, DG will directly supply electricity to the load. A battery bank of
HSAPV system serves as energy storage to provide a controlled form of electricity to meet the load demand. Instead, charge controllers control the process of charging the battery using the charge generated by the PV modules. Consequently, the inverter converts the DC signal into AC signal. This allows the PV to directly supply electricity to the load rather than having to inject the generated electricity from the utility grid. HSAPV system size becomes crucial since an undersized system may result in failure in meeting the load demand while an oversized system would undermine the techno-economic benefits of having such system as reported in [3]. The size of the HSAPV system appears to be more complex and difficult than the size of the photovoltaic system grid-connected since more components should be considered in the HSAPV system. In [4]-[5], the sizing parameters of the HSAPV system are more complicated since the system cannot receive immediate back-up from the utility grid. The size of the HSAPV system usually requires system designers to initially choose PV modules, charge controller, battery bank, and inverter before trying to match the electrical characteristics of these components.

Dimensioning of PV array and battery bank is an important process. This determines the technical performance of the system whether the desired value is 
achieved. However, if there is more than one HSAPV model, the sizing process is repeated to achieve the most suitable parameters for the design. The conventional sizing process has experienced computational burden as reported in [6]. Several studies have been conducted to accelerate the overall sizing process in HSAPV design. Most approaches made use of various types of Computational Intelligence (CI) techniques. One of the popular optimization techniques that have been widely employed is Artificial Intelligence (AI) [7]. AI technique has dealt with difficult problems in some areas; which in turns alleviated the setback experienced in the existing conventional techniques. There are three important components in AI namely, the Artificial Neural Network (ANN), Fuzzy Logic (FL) and Evolutionary Computation (EC) [7]. The three main branches of AI have their own different applications. For instance, ANN is used for prediction and forecasting; while Fuzzy Logic (FL) is used to make decisions. On the other hand, EC is commonly used for population-based metaheuristic optimization process. Generally, there are four main branches of Evolutionary Computation (EC) which are Genetic Algorithm (GA), Genetic Programming (GP), Evolutionary Strategy (ES) and Evolutionary Programming [7].

Design optimization forms an important part of any design problem in engineering and industry [8]. Among the popular optimization techniques are particle swarm optimization (PSO), Genetic Algorithm (GA), Ant Colony Optimization (ACO), Firefly Algorithm (FA) and many others. One of the works which can be highlighted related to this study is GA. GA has been used to determine the optimum configuration of renewable energy facilities on the islands of Japan for total cost can provide reduction scheme [8]. A similar study was conducted by Ramoji and Kumar in [9], to find the optimal size of each component in SAPV system to obtain minimum load demand. In addition, the implementation of PSO as the optimization technique has proven to reduce the annual cost of SAPV through the determination of the optimum number of PV modules and solar battery [10]-[11]. This paper presents a sizing optimization technique for Hybrid Stand-Alone Photovoltaic (HSAPV). Two optimization techniques have been developed, used to determine the optimum PV modules, charge controllers, inverters, battery and diesel generator. Comparative studies have been performed between FEP and CEP; while, the ISA used as the benchmark technique.

\section{MATERIAL AND METHOD}

This section presents the relevant algorithms for the proposed techniques, implemented in this study.

\section{A. System Description}

HSAPV system comprises solar PV modules, battery, charge controllers, inverters, and diesel generator. Fig. 1 shows the block diagram of HSAPV system. Prior to forming HSAPV system, load demand should be determined first.
The load demand will be supplied by the battery bank. Battery bank acts as a storage which provides DC signal to the inverter. The inverter converts $\mathrm{DC}$ voltage to AC voltage which then supplies the AC load. The storage can receive current supply from the fuel genset (diesel generator) via the battery charger. PV array collects sunlight which will feed to the charge controller. Charge controller controls the charging process of the battery bank. In case the PV does not receive sunlight, the charging process of the battery bank is taken over by the battery charger, which receives current from the fuel genset.

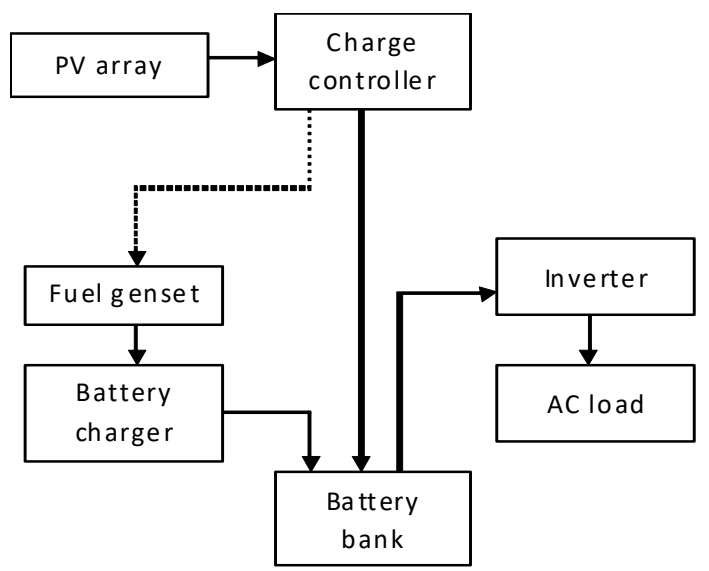

Fig. 1 Block diagram of HSAPV system

In this study, data were collected from a rural area in Kalabakan Sabah. Sabah is a state in East Malaysia located close to Brunei and Indonesia at Borneo Island. The estimated daily load demand and monthly solar radiations are shown in Table 1 and Table 2 respectively.

\section{B. Sizing Determination}

The sizing steps of HSAPV system are outlined below [12]:

\section{1) Load Profile}

Step 1: Determine the total energy required daily, $E_{\text {required_daily }}$

$$
\begin{aligned}
& E_{\text {requirad_tally }}=\frac{E_{A c}}{\eta_{\text {Inv }}} \\
& E_{A C}=\frac{F_{A c_{-} n}}{p f_{A c_{-} b_{1} d_{2} n}} X t_{\text {load } n}
\end{aligned}
$$

Where $E_{A C}$ is the total energy required daily for AC load as delivered by the battery in $\mathrm{Wh}, \eta_{i n v}$ is the average efficiency of the inverter used for the designed AC loads, $P_{A C_{-} n}$ is the power rating of the AC load in Watt, $p f_{A C_{-} l o a d \_n}$ is the power factor of the AC load and $t_{\text {load } n n}$ is the number of hours when the load is in use $h$.

Step 2: Determine the irradiation to load ratio, $R_{I L}$

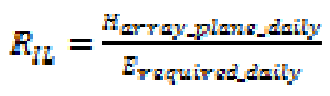


TABLE I

EXPECTED MONTHLy SOLAR IRRAdiation AT Site

\begin{tabular}{|c|c|c|c|c|c|c|c|c|c|c|c|c|}
\hline Month & Jan & Feb & Mar & Apr & May & Jun & Jul & Aug & Sep & Oct & Nov & Dec \\
\hline $\begin{array}{c}\text { Irradiation, G } \\
\left(\mathrm{Wh} / \mathrm{m}^{2}\right)\end{array}$ & 4000 & 4320 & 4400 & 4460 & 4500 & 4700 & 5100 & 5180 & 5100 & 5090 & 5110 & 5050 \\
\hline
\end{tabular}

TABLE II

DAILy LoAd PRofile of A House At SITE

\begin{tabular}{|c|c|c|c|c|c|c|c|c|}
\hline Appliance & $\begin{array}{c}\text { Number of } \\
\text { units }\end{array}$ & $\begin{array}{c}\text { Power } \\
\text { per unit }\end{array}$ & $\begin{array}{l}\text { Power } \\
\text { factor }\end{array}$ & $\begin{array}{l}\text { Usage } \\
\text { Times }\end{array}$ & Energy & $\begin{array}{l}\text { Usage } \\
\text { Times }\end{array}$ & Energy & $\begin{array}{l}\text { Surge } \\
\text { factor }\end{array}$ \\
\hline & & & & & $\begin{array}{c}\text { Dry season } \\
\text { (Jan..Jun) }\end{array}$ & & $\begin{array}{c}\text { Wet season } \\
\text { (Jul..Dec) }\end{array}$ & \\
\hline $240 \mathrm{ac}, 50 \mathrm{~Hz}$ & & $\mathrm{~W}$ & $\mathrm{~W}$ & $\mathrm{~h}$ & Wh & $\mathrm{h}$ & Wh & \\
\hline Water pump & 3 & 120 & 0.7 & 2 & 720 & 1 & 360 & 5 \\
\hline $\begin{array}{l}\text { Incandescent } \\
\text { bulb }\end{array}$ & 15 & 40 & 1 & 10 & 6000 & 13 & 7800 & 1 \\
\hline Television & 3 & 80 & 0.95 & 8 & 1920 & 6 & 1440 & 1 \\
\hline Stand fan & 3 & 60 & 0.6 & 4 & 720 & 10 & 1800 & 3 \\
\hline \multicolumn{5}{|c|}{ Daily Average AC Load Demand (Wh) } & 9360 & & 11400 & \\
\hline
\end{tabular}

Where $H_{\text {array_plane_daily }}$ is the daily solar irradiation on the array plane $\left(\mathrm{kWh} / \mathrm{m}^{2}\right)$.

Step 3: Calculate the system voltage (SV). The SV can be selected as $12 \mathrm{~V}, 24 \mathrm{~V}$ or $48 \mathrm{~V}$ depending on the size of the load demand as shown in Table 3. From this table, 3 cases have been considered.

TABLE III SELECTION OF SV [12]

\begin{tabular}{|c|c|c|}
\hline & Condition & $\begin{array}{c}\text { Recommended } \\
\text { SV }(\mathbf{V})\end{array}$ \\
\hline Case 1 & $E_{\text {required_daily }} \leq 1 \mathrm{kWh}$ & 12 \\
\hline Case 2 & $\begin{array}{c}1 \mathrm{kWh} \leq E_{\text {required_daily }} \leq 4 \\
\mathrm{kWh}\end{array}$ & 24 \\
\hline Case 3 & $E_{\text {required_daily }} \geq 4 \mathrm{kWh}$ & 48 \\
\hline
\end{tabular}

Step 4: Determine the total capacity required daily, $C_{\text {required_daily }}$

$$
G_{\text {Yequired_daily }}=\frac{E_{\text {raguirad_daily }}}{s V}
$$

2) Battery Sizing

Step 5: Determine the battery bank capacity required, $C_{\text {bank_required }}$

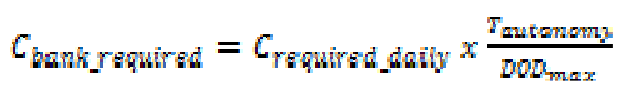

where $D O D_{\max }$ is the maximum battery depth of discharge. $T_{\text {autonomy }}$ represents the expected number of days that the load demand will be met by battery bank without sunlight availability.

Step 6: Determine the revised battery bank capacity required, $C_{\text {revised_bank_required }}$

$$
C_{\text {ravigad_bank_requirad }}=\frac{C_{\text {bank_raquirzd }}}{\text { fromg_antt }}
$$

Where $C_{\text {revised_bank_required }}$ is the revised battery bank capacity required and $f_{\text {temp_batt }}$ is the temperature correction factor of the battery.
Step 7: Calculate the total load current from the battery bank, Itotal_load_current and the battery bank discharge rate, $T_{\text {bank_disch }}$

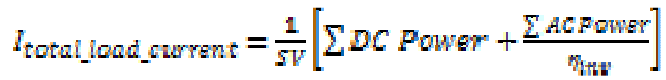

$$
\begin{aligned}
& T_{\text {bank_disch }}=\frac{\text { Gank_raquired }}{i_{\text {roral_lond_eurran }}}
\end{aligned}
$$

Where $T_{\text {bank_disch }}$ is the discharge rate of battery bank in $\mathrm{h}$.

Step 8: Determine the battery bank configuration, i.e., the number of battery in series string, $N_{\text {series_bank, number of }}$ battery strings in parallel, $N_{\text {parallel_bank }}$ and bank capacity of the selected battery, $C_{\text {bank_selected, }}$

$$
N_{\text {sarias_bank }}=\frac{S V}{V_{\text {nom_anth }}}
$$

where $V_{\text {nom_batt }}$ is the nominal battery voltage and $C_{\text {per_battery }}$ is the $\mathrm{AH}$ capacity which can be selected from the datasheet.

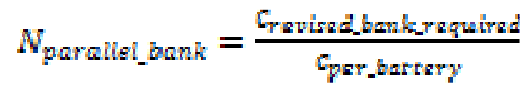

$$
\begin{aligned}
& C_{\text {bank_alectad }}=N_{\text {parallat_bank }} X C_{\text {par_battery }}
\end{aligned}
$$

Step 9: Determine the daily depth of discharge of the battery bank, $D O D_{d}$

$$
N_{\text {parallel_bank }}=\frac{\text { Cravisa_bank_raquiral }}{\text { Cpar_bartery }}
$$

where $D O D_{d}$ is the average daily depth of discharge of the battery bank.

\section{3) PV Sizing}

Step 10: It has two categories to determine the PV array configuration, i.e. for standard charge controller without MPPT, the number of PV modules connected in series per 
string, $N_{\text {series_pv }}$ and the number of PV modules connected in parallel per string, $\mathrm{N}_{\text {parallel_p }}$

$$
\begin{aligned}
& N_{\text {series_pv }}=\frac{s V}{V_{\text {nom_modula }}}
\end{aligned}
$$

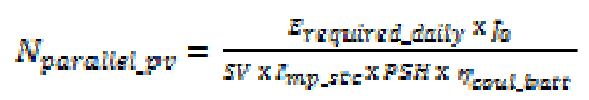

where $V_{\text {nom_module }}$ is the nominal voltage of the PV module. For $I_{m p \_s c}$ is the expected current at the maximum power at Standard Test Condition (STC). PSH is the number of daily peak sun hours which is associated to the amount of daily solar irradiation, $f_{o}$ is the coefficient for oversizing the $\mathrm{PV}$ array and $\eta_{\text {coul_batt }}$ is the coulombic efficiency of the battery.

Step 11: For PV configuration based on charge controller with MPPT; determine the maximum and a minimum number of series PV module based on open circuit voltage. $N_{\text {series_max_based_on_Voc }}$ and $N_{\text {series_min_based_on_Voc. }}$.

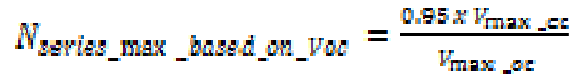

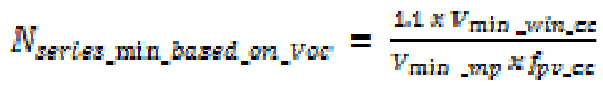

where $V_{\text {max_cc }}$ is the maximum input voltage rating of the charge controller, and $V_{\text {max_oc }}$ is the maximum open circuit voltage rating of PV module. $V_{\text {min_window_cc }}$ is the minimum allowable window input voltage to the MPPT of the charge controller, $V_{\text {min_mp }}$ is the minimum voltage at a maximum power of PV module, and $f_{p v_{-} c c}$ is cabling efficiency from PV to charge controller.

Step 12: Determine the maximum number of series PV module based on maximum power voltage, $N_{\text {max_series_based_on_Vmp }}$

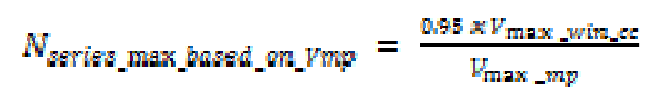

Where $V_{\text {max_win_cc }}$ is the maximum window voltage of the charge controller and $V_{\text {max } \_p}$ is the maximum voltage at maximum power at PV module.

Step 13: Determine the corrected output power of module, $P_{\text {mod_corrected }}$ and sub-system efficiency, $\eta_{p v_{-} s s}$

$$
P_{\text {mod_corrected }}=P_{\text {mp_stc }} X f_{\text {femp }} X f_{\text {mm }} X \text { fdirt }
$$

Where $P_{m p \_s t c}$ is the rated power at STC, $f_{\text {dirt }}$ is the derating factor for dirt, $f_{m m}$ is the derating factor of the manufacturing tolerance and $f_{\text {temp }}$ is the derating factor for temperature.

$$
\eta_{p p_{-} s}=\eta_{\text {pv_cable }} X \eta_{\text {cantroller }} X \eta_{\text {batt }}
$$

Where $\eta_{p v_{\text {cable }}}$ is the efficiency of cable from PV array to the battery, $\eta_{\text {controller }}$ is the efficiency of the MPPT charge controller and $\eta_{\text {batt }}$ is the efficiency of the battery.

Step 14: Determine the total number of PV modules for the PV array, $N_{T_{-} m p p t}$

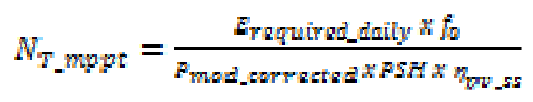

Where $\eta_{p v_{-} s s}$ is the sub-system efficiency of PV array, and $P_{m p \_s t c}$ is the rated maximum power at Standard Test Conditions (STC).

Step 15: Determine the total number of parallel PV modules, $N_{P \_m p p t}$,

$$
N_{F_{\text {mppt }}}=\frac{W_{I_{\text {_mppr }}}}{N_{z_{\text {_mppt }}}}
$$

where $N_{S_{-} m p p t}$ is the total number of PV modules in series between $N_{\text {series_max }}$ and $N_{\text {series_min }}$

Step 16: Determine the peak capacity of the array using the MPPT charge controller, $P_{\text {array_mppt_cc }}$

$$
P_{\text {array_magtac }}=P_{\text {ma_mod_st }} X N_{s_{-} \text {mope }} X N_{P_{-} \text {magt }}
$$

4) Inverter Sizing

Step 17: Determine the apparent power of the inverter required for 30 minutes at maximum demand.

$$
s_{\text {mw zomin }}=s_{\max \text { AC damand }} X S_{\text {mv }}
$$

Step 18: Determine the apparent power of the inverter required for surge demand.

$$
\begin{gathered}
S_{\text {inv_urge }}=S_{\text {max_AC_surge }} X S_{f f w} \\
S_{\text {max_AC_surge }}=\frac{F_{r a g l}}{P F} X S_{f}
\end{gathered}
$$

where $S_{\text {inv_30min }}$ is the apparent power of the inverter at maximum demand, $S_{\text {inv_surge }}$ is the surge rating of the inverter, $S_{\text {max_AC_surge }}$ is AC the surge load demand, $S_{\text {max_AC_demand }}$ is the maximum AC load demand, $S f_{i n v}$ is the safety factor of the inverter, $P_{\text {real }}$ is the real power consumption when running, $S_{f}$ is the surge factor, and $P F$ is the power factor.

5) Diesel Generator Sizing

Step 19: Determine the minimum size of diesel generator;

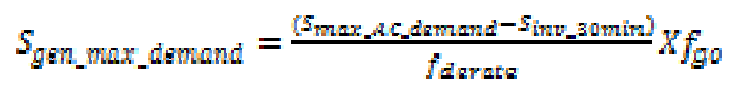

where $S_{\text {gen_max_demand_parallel }}$ is the minimum diesel generator rating based on power demand, $S_{\text {max_AC_demand }}$ is the maximum AC load, $\mathrm{S}_{\text {inv } 30 \text { min }}$ is the 30 minutes' apparent power rating of the inverter, $f_{g o}$ is diesel generator factor, and $f_{\text {derate }}$ is the total derating factor. $S_{\text {gen_max_surge }}$ can be calculated using Eq. (27).

$$
S_{\text {gen_max_Burge }}=\frac{\left(S_{\text {mas_Ac_rurga }}-S_{\text {inn_rurga }}\right)}{f_{\text {durara }}} X f_{\text {Go }}
$$

where $S_{\text {gen_max_surge }}$ is the minimum diesel generator rating based on surge condition, $S_{\text {max_AC_surge }}$ is the AC surge load demand, and $S_{\text {inv_surge }}$ is the surge rating of the inverter.

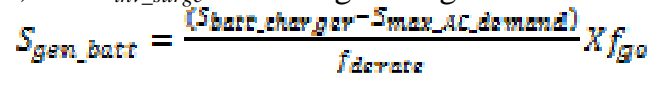


where $S_{\text {gen_batt }}$ is the diesel generator rating based on battery charging and maximum load demand.

6) Performance Ratio

Step 20: Determine the Performance Ratio, $P R$

$$
P R=\frac{s_{\text {sys_axp }}}{\text { Parray_re }_{\text {PSF }} \text { Panual }}
$$

where $E_{\text {sys_exp }}$ is the expected $\mathrm{kWh}$ output of the system and $P_{\text {array_stc }}$ is the nominal PV array power at STC. PSH represents the estimated annual PSH derived from Table 2.

\section{Evolutionary Programming Based Sizing Algorithm}

Nowadays, there are several types of EP that have been developed namely Classical EP, Adaptive EP, and Fast EP. Theoretically, there are 5 basic processes in EP, i.e., random initialization, fitness computation, mutation, combination, and selection. Generally, EP works based on a growing population of possible candidates for the optimal solution to the global optimal by the operator mutation and selection scheme. In this study, the EP has been used to optimize the parameters of the HSAPV design such as PV modules, batteries, charge controllers, diesel generator and inverters for PR maximization. Fig. 2 presents the flowchart of general EP.

The EP-based algorithm for optimization task is described as follows [13]:

Step 1: Generate $\mathrm{N}$ sets of random numbers x1, x2, x3, x4, and $x 5$. The control variables, i.e., $x 1, x 2, x 3, x 4$, and $x 5$ are utilized to represent the decision variables, namely the model of PV modules, battery, inverter, charge controller and diesel generator. Specifications of the HSAPV design will be based on the standard datasheet.

Step 2: Calculate the fitness value, i.e., PR for each set of random numbers. Sizing procedure described in Section II is executed to determine PR.

Step 3: Mutate each set of the individuals to produce offspring. Thus $\mathrm{N}$ offspring produced. Individual refers to the value of each parameter in the whole population. Conventionally, 20 individuals are formed in each population. Two mutation schemes were tested in this study, i.e., Gaussian and Cauchy mutation techniques. The EP with the Gaussian mutation is known as Classical Evolutionary programming (CEP) whereas the EP with the Cauchy mutation is known as Fast Evolutionary Programming (FEP) [14].

Step 4: Determine the fitness value of every offspring as described in step 2.

Step 5: Combine both parents and offspring. After that, the top $\mathrm{N}$ candidates are selected for the next generation based on the merit of their fitness values.

Step 6: At this stage, the individuals undergo convergence test as the stopping criterion. This is evaluated based on the difference between the value of maximum fitness and minimum fitness. This value can be set in accordance with the desired accuracy. The typical value for this criterion is 0.0001 . If this value is not achieved, the next evolution or iteration will repeat.

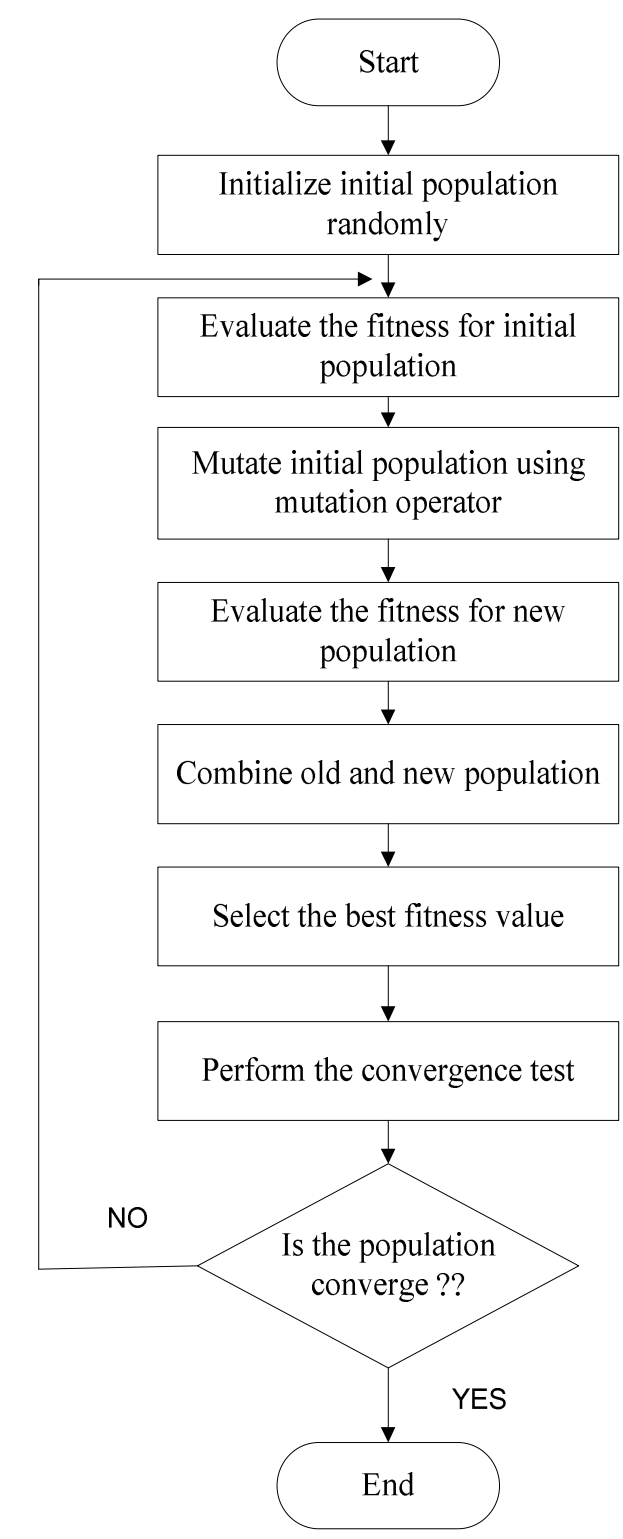

Fig. 2 Flowchart of evolutionary programming (EP).

\section{RESULTS AND DISCUSSION}

Rigorous studies have been conducted to evaluate the effectiveness of the proposed FEP and CEP in addressing the HSAPV design in renewable energy. Table 4 tabulates the results for performance ratio (PR), implemented using FEP, CEP, and ISA. From the table, it is observed that all the three techniques ISA, CEP, and FEP determine no of battery code is 12. This implies that all the techniques agreed on each other. The number of PV code identified by ISA and FEP is identical, i.e., 12; while, CEP determines 6 as the PV code value. ISA parameters are used as the benchmarking for the whole design of HSAPV. 
TABLE IV

PERFORMANCE OF COMPARISON EP MODELS WITH ISA

\begin{tabular}{|c|c|c|c|}
\hline \multirow{2}{*}{ Results } & \multirow{2}{*}{ ISA } & \multicolumn{2}{|c|}{ EP Techniques } \\
\cline { 3 - 4 } & & CEP & FEP \\
\hline Battery code & 12 & 12 & 12 \\
\hline PV code & 12 & 6 & 12 \\
\hline Inverter code & 7 & 7 & 7 \\
\hline $\begin{array}{c}\text { Charge } \\
\text { Controller code }\end{array}$ & 7 & 8 & 7 \\
\hline $\begin{array}{c}\text { Diesel Generator } \\
\text { Code }\end{array}$ & 11 & 11 & 11 \\
\hline N_batt_s & 8 & 8 & 8 \\
\hline N_batt_p & 2 & 2 & 2 \\
\hline N_pv_s & 2 & 3 & 2 \\
\hline N_pv_p & 8 & 6 & 8 \\
\hline Nt_inv & 1 & 1 & 1 \\
\hline Nt_cc & 2 & 2 & 2 \\
\hline Nt_diesel_gen & 1 & 1 & 1 \\
\hline Optimal, PR & 0.7682 & 0.7428 & 0.7682 \\
\hline Comp. time, (s) & 1102.00 & 120.58 & 117.58 \\
\hline
\end{tabular}

The values of diesel generator code, no of battery in series (N_batt_s), no of battery in parallel (N_batt_p), the total number of the inverter ( $\mathrm{Nt}$ inv), the total number of the charge controller (Nt_cc) and the total number of diesel generator (Nt_diesel_gen) are following in accordance to the benchmark values (ISA). This indicates that the implementation of FEP and CEP techniques have successfully achieved the benchmark values for all the mentioned parameters. Nevertheless, FEP has expedited the computation time to achieve minimal value. FEP managed to achieve an optimal solution within 117.58 seconds. This result exhibits $89.33 \%$ faster than ISA technique.

Further analysis can be conducted by looking at the effect of population size in achieving the optimal solution. The results for performance ratio (PR) implemented using FEP, CEP, and ISA at incremental population size are presented in Fig. 3. From the figure, at a small population size $(n=5)$, the achievable maximum PR is slightly lower than 0.71 for CEP (i.e., 0.706), while its value is slightly higher than 071 (i.e., 0.712 optimized using FEP. The PR values increase accordingly as the population size is increased. Nevertheless, the population size of 20 managed to achieve the highest maximum PR value as those set by ISA. This implies that FEP is superior to CEP in optimizing the HSAPV parameters for maximization of PR. Further increment in population size does not increase its performance; rather suffers the performance of PR. In addition, the sizing algorithm of CEP and FEP were compared with the benchmarked of sizing algorithm using an iterative approach, known as ISA. The results are shown in Table 4. FEP shows that to produce the similar PR with ISA. Instead, CEP can get the optimum PR as generated by ISA. Based on computation time, FEP is much faster than ISA.

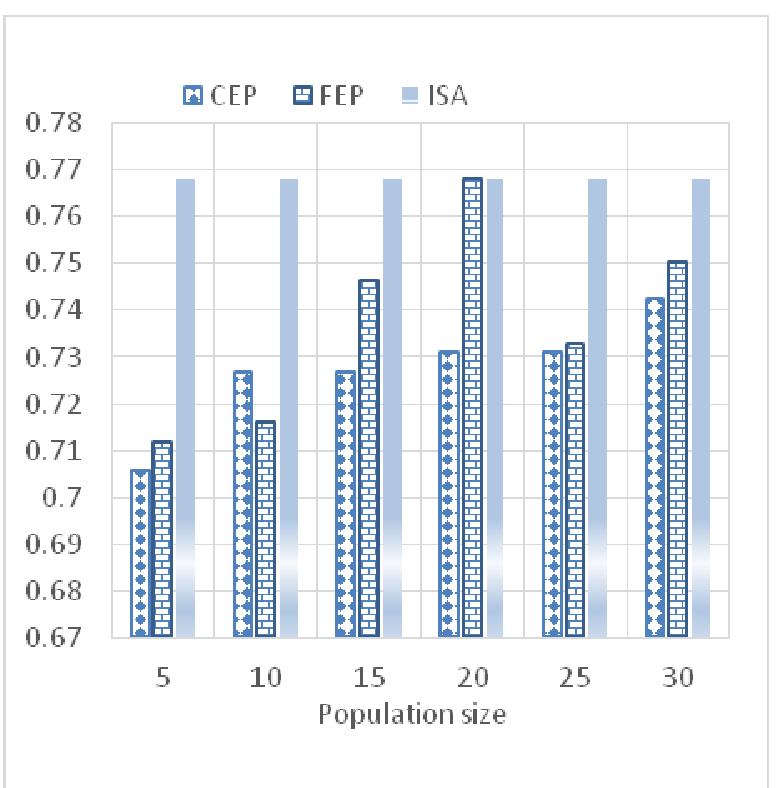

Fig. 3 Performance ratio with different EP models and ISA at different number of iteration

\section{CONCLUSIONS}

This paper has presented sizing optimization technique for Hybrid Stand-Alone Photovoltaic (HSAPV). In this study, two different EP techniques termed as FEP and CEP have been developed and implemented in the design of HSAPV system. Results obtained from the study demonstrated that application of FEP has significantly achieved the maximum PR values, within minimal computation time. This reveals the superiority of FEP over CEP in addressing HSAPV design. Further problems in similar studies can adopt the same technique, making it feasible is solving other problems. The developed FEP is also feasible for solving other optimization problems. A minor alteration in the developed algorithm could be done to suit the future problem formulations.

\section{ACKNOWLEDGMENT}

The authors would like to acknowledge The Institute of Research Management and Innovation (IRMI) UiTM, Shah Alam, Selangor, Malaysia and Ministry of Higher Education (MOHE) for the financial support of this research. This research is supported by MOHE under the research Acculturation Grant Scheme (RAGS) with project code: 600-RMI/RAGS 5/3 (187/2014).

\section{REFERENCES}

[1] W.Z. Leow, Y.M. Irwan, M. Irwanto, M. Isa, A.R. Amelia and I Safwati,"Temperature Distribution of Three-Dimensional Photovoltaic Panel by Using Finite Element Simulation," International Journal on Advanced Science Engineering Information Technology, pp. 607-612, 2016.

[2] A. F. Hamamy and O. A. Maliki, " Future Solar Irradiance Prediction using Least Square Support Vector Machine," International Journal on Advanced Science Engineering Information Technology, pp. 520523, 2016.

[3] L. Hontoria, J. Aguielera, and P. Zufiria, "A new approach for sizing stand-alone photovoltaic systems based in neural networks," Solar Energy, vol. 78, no. 2, pp. 313-319, February 2005. 
[4] A. E. A. Nafeh, "Proposed technique for optimally sizing a PV/diesel hybrid system," in International Conference on Renewable Energies and Power Quality, Spain, 2010.

[5] S. H. El-Hefnawi, "Photovoltaic diesel-generator hybrid power system sizing," Renewable Energy, vol. 13, no. 1, pp. 33-40, January 1998.

[6] S. Sulaiman, T. Rahman, and I. Musirin, "Artificial immune system for sizing grid connected photovoltaic system," in $5^{\text {th }}$ International Power Engineering and Optimization Conference (PEOCO), 2011, pp. 398-403.

[7] D. Kothari, "Power system optimization in Computational Intelligence and Signal Processing (CISP)," in 2012 2nd National Conference on, 2012, pp. 18-21.

[8] S. W. Xiang, "Design of stand-alone photovoltaic system at minimum cost in Malaysia," in International Conference on Industrial Electronics and Applications, Singapore, 2008, pp. 702707.

[9] S. K. Ramoji and B. J. Kumar, "Optimal Economical sizing of a PVWind Hybrid Energy System using Genetic Algorithm and Teaching Learning Based Optimization," International Journal of Advanced Research in Electrical, Electronics and Instrumentation Engineering, vol. 3, February 2014, pp. 1-16,
[10] A. Kaabeche, M. Belhamel, and R. Ibtiouen, "Sizing optimization of grid-independent hybrid photovoltaic/wind power generation system," Energy, vol. 36, no. 2, pp. 1214-1222, February 2011.

[11] A. B. Kanase-Patil, R. P. Saini, and M. P. Sharma, "Sizing of integrated renewable energy system based on load profiles and reliability index for the state of Uttarakhand in India," Renewable Energy, vol. 36, no. 11, pp. 2809-2821, November 2011.

[12] A. M. O. Sulaiman Shaari, Ahmad Hadri Haris, Shahril Irwan Sulaiman, Solar Photovoltaic Power: Designing Stand-Alone System, 1 ed. Malaysia: Ministry of Energy,Green Technology and Water, 2010 .

[13] A. Aziz, N. Izzati, S. I. Sulaiman, I. Musirin, and S. Shaari, "New Technique For Optimization Technique Of A Stand-Alone Photovoltaic System," in Journal of Theoretical and Applied Information Technology, vol. 67 No.2, pp. 533-538.

[14] A. Aziz, N. Izzati, S. I. Sulaiman, I. Musirin, and S. Shaari, "Assessment of evolutionary programming models for singleobjective optimization," in IEEE 7th International Power Engineering and Optimization Conference (PEOCO), 2013, pp. 304-308. 